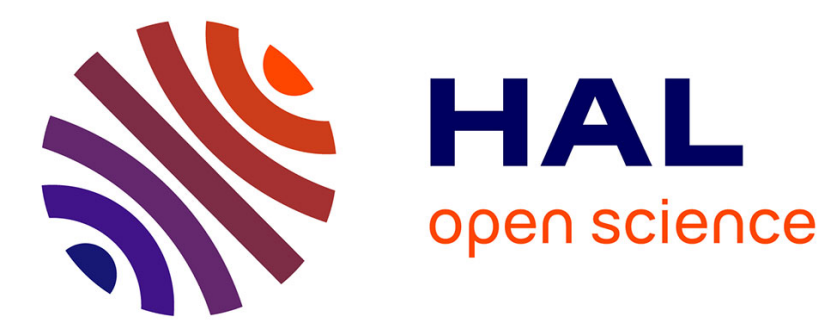

\title{
Ordering Minimalist Bridged Polysilsesquioxane Films under 1 Visible LED Light Irradiation
}

\author{
Lingli Ni, Mei Wu, Feng Chen, Irena Deroche, Abraham Chemtob
}

\section{To cite this version:}

Lingli Ni, Mei Wu, Feng Chen, Irena Deroche, Abraham Chemtob. Ordering Minimalist Bridged Polysilsesquioxane Films under 1 Visible LED Light Irradiation. Soft Materials, 2017, 15 (2), pp.196204. 10.1080/1539445X.2017.1308380 . hal-02539023

\section{HAL Id: hal-02539023 \\ https://hal.science/hal-02539023}

Submitted on 9 Apr 2020

HAL is a multi-disciplinary open access archive for the deposit and dissemination of scientific research documents, whether they are published or not. The documents may come from teaching and research institutions in France or abroad, or from public or private research centers.
L'archive ouverte pluridisciplinaire HAL, est destinée au dépôt et à la diffusion de documents scientifiques de niveau recherche, publiés ou non, émanant des établissements d'enseignement et de recherche français ou étrangers, des laboratoires publics ou privés. 
$4{ }^{\dagger}$ Key Laboratory for Palygorskite Science and Applied Technology of Jiangsu Province, College of

5 Chemical Engineering, Huaiyin Institute of Technology, 223003 Huaian, People's Republic of

6 China Jean Starcky 68057 Mulhouse Cedex, France

9 10

11

12

13

14

\section{Visible LED Light Irradiation}

\author{
Lingli Ni, ${ }^{* \dagger}$ Mei Wu,${ }^{\dagger}$ Feng Chen, ${ }^{\dagger}$ Irena Deroche, ${ }^{\S}$ Abraham Chemtob, ${ }^{\S}$
}

${ }^{\S}$ Institute of Material Science of Mulhouse, CNRS, UMR 7361, University of Haute-Alsace, 15 rue

\section{*Corresponding author:}

Dr. Lingli Ni; E-mail: nilingli520@126.com; Tel: +86 5178355 9056; Fax: +86 51783559056 
A visible light-mediated sol-gel process can promote the ordering of hexylene, octylene and decylene-bridged polysilsesquioxane with very simple organosilane building blocks having only a short alkylene bridging group: $\left(\mathrm{CH}_{3} \mathrm{O}\right)_{3} \mathrm{SiC}_{\mathrm{n}} \mathrm{H}_{2 \mathrm{n}} \mathrm{Si}\left(\mathrm{OCH}_{3}\right)_{3}(\mathrm{n}=6,8,10)$. Photocondensation and self-assembly of films are promoted through exposure to a light-emitting diode $(405 \mathrm{~nm})$. The solvent-free synthesis involves very low light intensity $\left(0.1 \mathrm{~mW} / \mathrm{cm}^{2}\right)$ and a minimum amount of photoacid generator $(0.5 \mathrm{wt} \%)$ acting as photocatalyst. X-ray diffraction and scanning electron microscopy prove the high level of organization, while real-time Fourier transform infrared spectroscopy shows conformational ordering of alkylene chains throughout irradiation. Molecular modeling reveals a multilayer structure based of the stacking of a single polysiloxane chain, with organic groups attached to adjacent Si atoms showing up and down orientation. 


\section{Introduction}

Self-directed organosilane assembly via sol-gel process is an attractive route to synthesize highly ordered polysilsesquioxanes (SQs) (1-5). In contrast to most sol-gel materials, these organosilica hybrids have the unique feature of being mesoscopically organized without the need for additional surfactant, which enables a single step synthesis and brings added value for many different applications including photonics (6) and smart devices (7). Central to self-organization is the development of strong enough secondary interactions (i.e. van der Waals, $\pi-\pi$ stacking and H-bonding) between the specific organic moieties of the organosilane precursors to overcome the disorder forces induced by random silanol condensation reactions (8-15). To achieve this, particular precursor architectures are necessary as well as a high level of control of sol-gel process since any change of temperature, solvent, catalyst or concentration may encourage or limit the self-assembly mechanism. Only a handful of precursors have so far resulted in SQs possessing long range organization. The typical organosilane architecture comprises two specific structural features: mono- or bis-sylilated terminal groups together with an organic moiety able to develop hydrophobic interactions (long enough alkyl or alkylene chains) or/and hydrogen bonds (ureido, amide groups), $\pi$ - $\pi$ stacking etc. $(1,16,17)$. Recently, our group introduced a different photochemical route to synthesize highly ordered SQs (18-21). In this approach, an organosilane-based film is irradiated in bulk in the presence of Brönsted superacids generated in situ by the UV-decomposition of a photoacid generator (PAG) based on diaryliodonium $\left(\mathrm{Ph}_{2} \mathrm{I}^{+} \mathrm{X}^{-}\right)$or triarylsulfonium $\left(\mathrm{Ph}_{3} \mathrm{~S}^{+} \mathrm{X}^{-}\right)$salts. Compared to conventional sol-gel process, photopolymerization offers several conventional advantages such as storable, ready-to-use, solvent-free formulation with no pot-life issue since the photocatalyst (photoacid) is released on demand. Additionally, two aspects are particularly meaningful and appropriate to self-assembly: the facile control of condensation rates (via irradiance) and water concentration within the film (via relative humidity: $\mathrm{RH}$ ). The former can 
prevent early gelation that would kinetically trap the system in a transient non-ordered state, while the latter can enhance the hydrophilic/hydrophobic contrast, and drive ultimately nanophase segregation. This offers a unique level of kinetic and thermodynamic control to mediate self-assembly. Both passive (alkyl/alkylene) (19-21) and active (ester, carboxylic acid functionalized) (18) lamellar hybrids have already been achieved via photoacid-catalyzed sol-gel process.

At this stage, other important questions arise concerning the development of self-directed organosilane sol-gel photopolymerization: firstly, can we make the process less demanding in terms of precursor's structure? In other, words, the challenge is to promote SQ ordering with the simplest building blocks possible, e.g. bridged precursors containing only short alkylene group such as hexylene, octylene and decylene. An objective like this has proven to be unattainable under conventional sol-gel process $(22,23)$. Secondly, how can processing conditions be improved in terms of eco-efficiency? Clearly, the best solution today is to rely on energy-saving and safer visible light-emitting diodes (LEDs) instead of $\mathrm{Hg}$ arc lamps. These two important issues have been addressed in details in the present report.

(i). Ordering minimalist precursors. Since interchain cohesion via van der Waals interactions increases with increasing length of the hydrophobic group, there is often a direct relationship between the level of ordering of the alkylene bridged SQ and the organic chain length. The concept of sufficient hydrophobic chain length for self-assembly is not unique to organosilane, but also controls surfactant micellization or liquid crystal formation. For example, below 10 carbons, salts of straight-chain fatty acids $\left(\mathrm{C}_{\mathrm{n}} \mathrm{H}_{2 \mathrm{n}+1} \mathrm{COO}^{-} \mathrm{M}^{+}\right)$are too soluble to have surface activity in water (24). Consequently, achieving long-range organization with hydrocarbon-based hydrophobic group shorter than $\mathrm{C}_{10}$ has never been described in the literature (23). Zhao and al. reported in 2006 hexylene- and octylene-Bridged SQ using either surfactant templating or high dilution conditions resulting in dimer structure $\left(\mathrm{T}^{1}\right.$ siloxane species only) and not a 
cross-linked siloxane structure (25). As shown in Scheme 1, the present study focuses on the comparative self-assembly and condensation of three bridged precursor films: $\left(\mathrm{CH}_{3} \mathrm{O}\right)_{3} \mathrm{SiC}_{\mathrm{n}} \mathrm{H}_{2 \mathrm{n}} \mathrm{Si}\left(\mathrm{OCH}_{3}\right)_{3}(\mathrm{n}=6,8,10)$ denoted as $\mathrm{BC}_{\mathrm{n}} \mathrm{TMS}$.

(ii). Improving photoprocess eco-effciency. Medium-pressure mercury arc lamp is the workhorse in radiation curing, and the main energy source used in all studies dealing with sol-gel photopolymerization. However, such lamp is energy intensive, involves toxic heavy metal, requires cooling system and operates under high voltages. In this work, we used a visible LED irradiation at $405 \mathrm{~nm}$ in the presence of an adequate visible light non-ionic PAG [(5-propylsulfonyloxyimino-5H-thiophen-2-ylidene)-2-methylphenyl-acetonitrile], releasing $n$-propane sulfonic acid catalyst. Ozone-free and mercury-free visible LED control offers significant advantages over mercury arc lamp, including lower cost, high monochromaticity, safer emission wavelength, smaller heat generation, longer life time (26-29). To the best of our knowledge, it is the first use of LED for the synthesis of highly organized lamellar SQ.

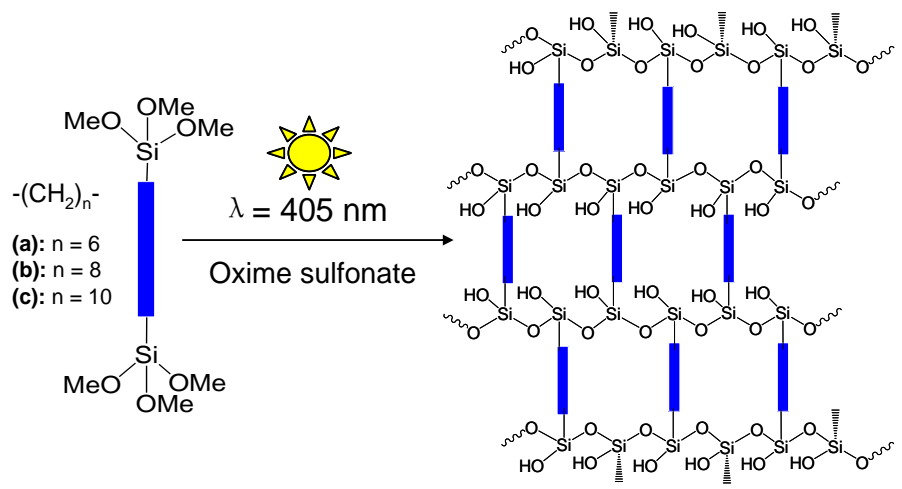

Scheme 1. Visible LED-activated sol-gel polymerization process of alkylene-bridged trimethoxysilane precursors $\mathrm{BC}_{\mathrm{n}} \mathrm{TMS}\left[\left(\mathrm{CH}_{3} \mathrm{O}\right)_{3} \mathrm{SiC}_{\mathrm{n}} \mathrm{H}_{2 \mathrm{n}} \mathrm{Si}\left(\mathrm{OCH}_{3}\right)_{3}, \mathrm{n}=6\right.$ (a), 8 (b), 10 (c)].

\section{Experimental section}

\subsection{Chemicals}

1,6-Bis(trimethoxysilyl)hexane (95\%) and 1,8-bis(trimethoxysilyl)octane (95\%) were supplied by Gelest. Trimethoxysilane and 1,9-decadiene were purchased from Aladdin and TCI chemicals (Shanghai), 
respectively. Nonionic photoacid generator Irgacure PAG103

[(5-propylsulfonyloxyimino-5H-thiophen-2-ylidene)-2-methylphenyl-acetonitrile] was provided by BASF. All of the chemicals were used as received.

\subsection{Synthesis of 1,10-Bis(trimethoxysilyl)decane}

1,10-Bis(trimethoxysilyl)decane was prepared according to the previous literature procedure (30). Typically, $6.9 \mathrm{~g}$ of 1,9-decadiene $(0.05 \mathrm{~mol}), 12.3 \mathrm{~g}$ of trimethoxysilane $(0.1 \mathrm{~mol})$ and $0.35 \mathrm{ml}$ of chloroplatinic acid in isopropanol $\left(2.73 \times 10^{-3} \mathrm{M}\right)$ were mixed together by magnetic stirring, then the mixture were heated to $100{ }^{\circ} \mathrm{C}$ and refluxed for 6 hours under nitrogen atmosphere. After distillation of the reaction mixture under vacuum, $6.7 \mathrm{~g}$ (35\% yield) of 1,10-Bis(trimethoxysilyl)decane was collected. ${ }^{1} \mathrm{H}$ NMR (400 $\left.\mathrm{MHz}, \mathrm{CDCl}_{3}\right): \delta(\mathrm{ppm}) 0.58(\mathrm{t}, 4 \mathrm{H}), 1.17-1.6(\mathrm{~m}, 34 \mathrm{H}), 3.7(\mathrm{q}, 12 \mathrm{H}) ;{ }^{13} \mathrm{C} \mathrm{NMR}\left(100 \mathrm{MHz}, \mathrm{CDCl}_{3}\right): \delta(\mathrm{ppm})$ $10.3,18.3,22.7,29.2,29.5,33.2,58.2$.

\subsection{Synthesis of hybrid films derived from alkylene-bridged trimethoxysilane precursors}

In a typical procedure, photoacid generator (PAG103, $0.5 \% \mathrm{wt}$ ) was dissolved in a $\mathrm{BC}_{\mathrm{n}} \mathrm{TMS}$ precursor to form a photolatent solution in the absence of light $(\lambda<500 \mathrm{~nm})$. The $\lambda_{\max }$ absorption of this PAG is located at $405 \mathrm{~nm}$ (31), which overlaps quite well with the LED emission spectrum spanning 385-420 nm (Figure S1, ESI). Then the resultant formulation was deposited on a silicon wafer by spin coating (1000 rpm, $20 \mathrm{~s})$ to produce a liquid film $(\sim 3 \mu \mathrm{m})$. Irradiation was provided at room temperature by a LED lamp (Shenzhen xianghe, $20 \mathrm{~W}$ ) at an incident light intensity of $0.1 \mathrm{~mW} / \mathrm{cm}^{2}$. The samples were irradiated during $30 \mathrm{~min}$ to yield solid SQ films $(\sim 4 \mu \mathrm{m})$. The relative humidity $(\mathrm{RH})$ during irradiation was controlled by using a saturated $\mathrm{NaCl}$ solution in a customized environmental cell. The resulting samples were characterized by a range of techniques: FTIR, X-ray diffractions (XRD), scanning electron microscopy (SEM), ${ }^{29} \mathrm{Si}$ solid state NMR. 


\subsection{Characterization}

Infrared spectra were recorded by a Nicolet-5700 Fourier transform infrared spectrophotometer. The resolution of the infrared spectra was $2 \mathrm{~cm}^{-1}$. X-ray diffraction patterns (XRD) were obtained on a Bruker D8-Discover diffractometer with fixed slits using $\mathrm{Cu} / \mathrm{K} \alpha$ radiation $(\lambda=1.5418 \AA)$ and $\theta-2 \theta$ mounting. Before analysis, films on silicon wafers were directly deposed on a plastic sample holder. Data were collected between 1 and $30^{\circ} 2 \theta$ degrees (XRD) with a scanning step of $0.01^{\circ} \mathrm{s}^{-1}$. Birefringent properties of the hybrid films were investigated by the polarized optical microscope (POM) of Leica DMLP. Morphologies of the samples were characterized by scanning electron microscopy (SEM, Hitachi S3000N microscope working at $25 \mathrm{kV})$. The samples being non-conductive, they have been metalized with gold (15 nm thickness). The transmission electron microscopy (TEM) observations were performed with a FEI TECNAI G ${ }^{2}$ TF20 microscope operating at $200 \mathrm{kV}$. The samples for TEM measurements were prepared by dropping their water suspensions onto the surface of copper observation grids. The ${ }^{29} \mathrm{Si}$ cross polarization magic angle spinning (CP-MAS) solid state NMR spectra was performed on a Bruker Avance III 400 spectrometer with a Bruker double channel $7 \mathrm{~mm}$ probe. In this case, zirconium rotors were employed at $79.48 \mathrm{MHz}$ using a recycling delay of $5 \mathrm{~s}$, a spinning frequency of $4 \mathrm{kHz}$ and a contact time of $4 \mathrm{~ms} .{ }^{29} \mathrm{Si}$ chemical shift is relative to tetramethylsilane. The condensation degree of the siloxane network was calculated according to the equation of $C D(\%)=\sum_{n} n \frac{T^{n}}{f}$, where $\mathrm{n}$ is the siloxane bonds attached to the central silicon functionality ( $\mathrm{f}=3$ here).

The geometry optimization of the ordered SQ structures was obtained through the energy minimization of the microscopic structural models prepared from scratch, using Forcite, the molecular mechanics module implemented within the Molecular Studio package. The calculations were based on the Dreiding force field, suited for a hybrid $\mathrm{SiO}_{2}$ - organic system, using default database parameters and the conjugate gradient minimization algorithm with following convergence criteria: $5.0 \times 10^{-5} \mathrm{kcal} / \mathrm{mol}, 0.002 \mathrm{kcal} /(\mathrm{mol} \cdot \AA)$, and 


\section{Results and discussion}

\subsection{Efficiency of visible LED activated sol-gel photopolymerization} $\mathrm{mW} / \mathrm{cm}^{2}$ ) during $30 \mathrm{~min}$, leading to solid hybrid coating. Efficiency of the photoinduced sol-gel polymerization was first assessed by FTIR spectroscopy. Figure 1 shows the FTIR spectrum of the nanocomposite films derived from $\mathrm{BC}_{6} \mathrm{TMS}\left(\mathrm{BC}_{6} \mathrm{SQ}\right)$ as well as that of the precursor (spectra of the other nanocomposite films derived from $\mathrm{BC}_{8} \mathrm{TMS}$ and $\mathrm{BC}_{10} \mathrm{TMS}$ are provided in Figure $\mathrm{S} 2$ of ESI). The sharp and strong $\mathrm{CH}_{3}$ symmetric stretch assigned to methoxysilyl group $\left(\mathrm{Si}-\mathrm{O}-\mathrm{CH}_{3}\right)$ at $2840 \mathrm{~cm}^{-1}$ almost vanished after UV exposure, suggesting a high hydrolysis degree (>97\%). Meanwhile, a broad band arose in the spectral region spanning 3000-3700 $\mathrm{cm}^{-1}$ attributed to O-H stretching vibrations of the newly created silanols (Si-OH). In accordance with hydrolysis reactions, a strong band at $930 \mathrm{~cm}^{-1}$ appeared due to the $\mathrm{Si}-\mathrm{O}$ stretching vibration of silanols. The presence of asymmetric stretching bands of siloxane bonds ( $\mathrm{Si}$-O-Si) at 1100, 1070 and $790 \mathrm{~cm}^{-1}$ proved finally the formation of SQ network. Similar observations were also observed for the other two precursors of $\mathrm{BC}_{8} \mathrm{TMS}$ and $\mathrm{BC}_{10} \mathrm{TMS}$.

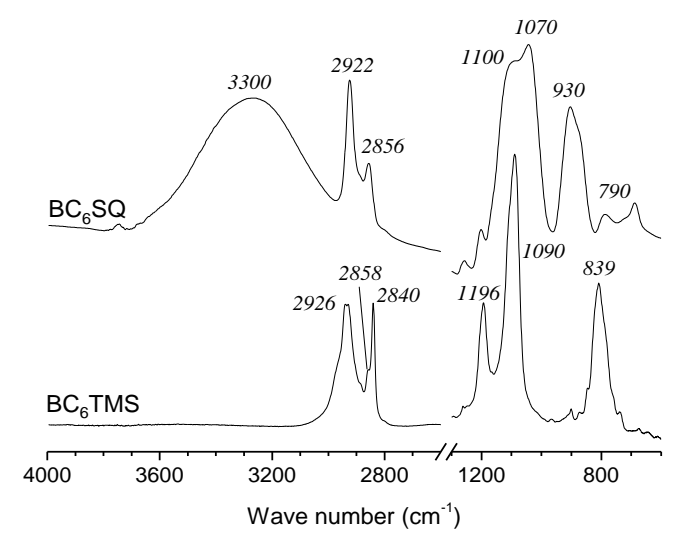

Figure 1. FTIR spectra of BC6TMS film before and after the sol-gel photopolymerization in the presence of PAG. 


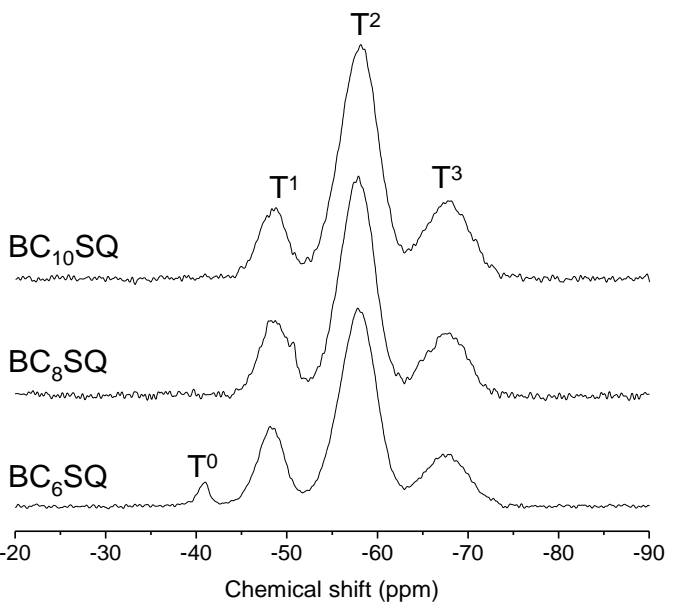

Figure 2. ${ }^{29} \mathrm{Si}$ solid state CP-MAS NMR spectra of the visible LED cured $\mathrm{BC}_{\mathrm{n}} \mathrm{SQ}$ hybrid films derived from $\mathrm{BC}_{\mathrm{n}} \mathrm{TMS}$ precursors.

\subsection{Photoinduced ordering of alkylene bridged polySQ films}

Figure 3 displays the X-ray diffraction patterns of the visible LED-cured alkylene bridged SQ films yields a lamellar structure with (001) and (003) reflections, indicating a basal spacing value of approximately 
$\left(\mathrm{HOSiC}_{\mathrm{n}} \mathrm{H}_{2 \mathrm{n}} \mathrm{Si}-\mathrm{OH}, \mathrm{n}=6,8\right.$ or 10$)$ with amphiphilic structures has been generated. Increasing the length of the bridging group has the effect of enhancing the intermolecular or intramolecular London dispersion forces between alkylene chains, and emphasizing the hydrophilic-hydrophobic contrast between the two moieties of the surfactant. Those two aspects result in greater enthalpic association forces, leading to a higher organization with longer alkylene chains. Additionally, we note that the basal spacing value of $\mathrm{BC}_{8} \mathrm{SQ}$ and $\mathrm{BC}_{10} \mathrm{SQ}$ also increased to $14.2 \AA$ and $16.2 \AA$ respectively. One should also emphasize the difference with periodically ordered mesoporous hybrids extensively investigated in the literature $(2,34)$ because in the present case the supramolecular assembly process results from the organosilica species themselves and no longer from a self-directing agent. Consequently, our SQ structure exhibit a long-range order arising from organized organic units and not from mesopores.

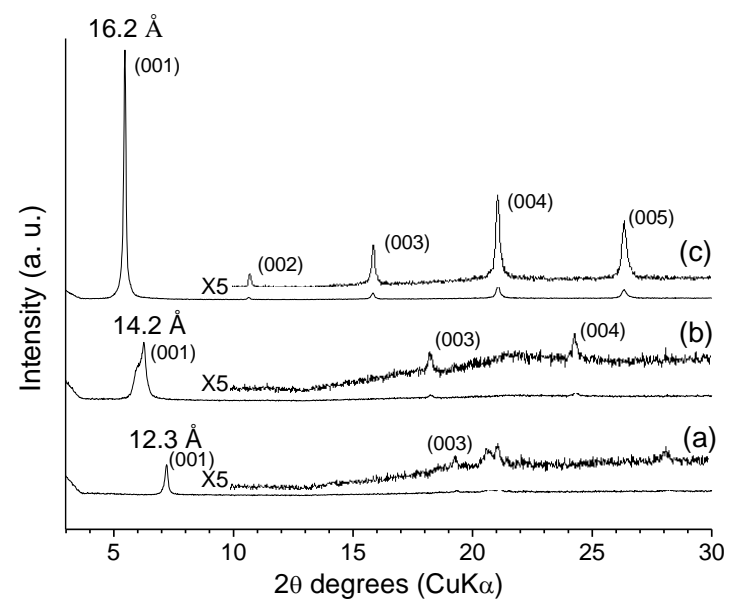

Figure 3. XRD patterns of the visible LED cured $\mathrm{BC}_{\mathrm{n}} \mathrm{SQ}$ hybrid films derived from $\mathrm{BC}_{\mathrm{n}} \mathrm{TMS}$ precursors $\left[\left(\mathrm{CH}_{3} \mathrm{O}\right)_{3} \mathrm{C}_{\mathrm{n}} \mathrm{H}_{2 \mathrm{n}}\left(\mathrm{OCH}_{3}\right)_{3}, \mathrm{n}=6(\mathbf{a}), 8(\mathbf{b}), 10(\mathbf{c})\right]$.

Further investigation of hybrid film nanostructure was performed by a set of microscopy techniques.

SEM observations revealed that all of these three products had lamellar morphology (Figure 4, left column).

As displayed in Figure 4 of right column, the POM images of $\mathrm{BC}_{6} \mathrm{SQ}(\mathbf{a})$ and $\mathrm{BC}_{8} \mathrm{SQ}$ (b) showed a regular and well-defined shape indicative of their crystalline nature. They both had quite homogeneous worm-like birefringent domains, suggesting a microscopic anisotropic organization. Clearly, more results about 
molecular orientational and conformational behavior in these anisotropic hybrid materials could be extracted from polarized FTIR. Nevertheless, only $\mathrm{BC}_{10} \mathrm{SQ}$, revealed unambiguously a strip-shaped structures by TEM as shown in Figure 5. Short bridging groups impose low interlamellar distance, that makes the observation difficult with a conventional (non high resolution) TEM.
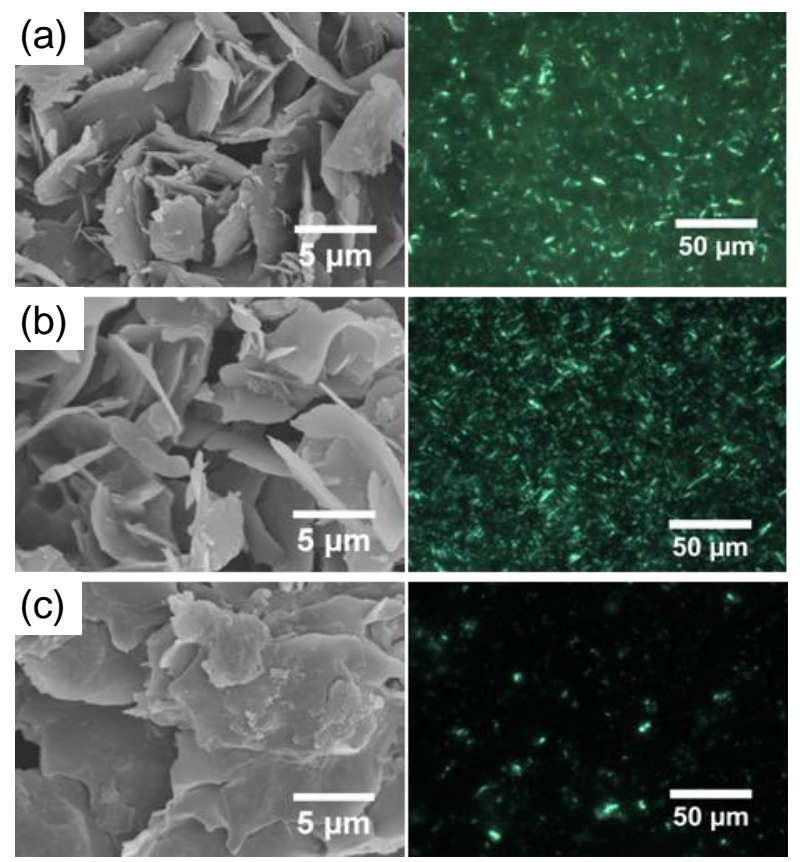

Figure 4. $\mathrm{SEM}$ and $\mathrm{POM}$ micrographs of the visible light cured $\mathrm{BC}_{\mathrm{n}} \mathrm{SQ}$ hybrid films: (a) $\mathrm{BC}_{6} \mathrm{SQ}$, (b) $\mathrm{BC}_{8} \mathrm{SQ}$, (c) $\mathrm{BC}_{10} \mathrm{SQ}$.

In addition, alkylene chain conformation has been investigated by FTIR characterization. C-H stretching region between 3000 to $2800 \mathrm{~cm}^{-1}$ holds valuable information as regards hydrocarbon chain environment and conformation (35-37). For instance, antisymmetric $\left(d^{-}\right)$and symmetric $\left(d^{+}\right)$stretching vibration of methylene group $\left(-\mathrm{CH}_{2}-\right)$ arose respectively at $2920 \mathrm{~cm}^{-1}$ and $2850 \mathrm{~cm}^{-1}$ in crystalline polyethylene; while in solution, they shift at $2926 \mathrm{~cm}^{-1}$ and $2854 \mathrm{~cm}^{-1}$ due to a greater incidence of gauche defects. Figure 6 displays the evolution of the $\mathrm{C}-\mathrm{H}$ stretching region during the photopolymerization of the three $\mathrm{BC}_{\mathrm{n}} \mathrm{TMS}$ precursors. Prior to irradiation, broad $d$ and $d^{+}$absorption bands were found at $2926 \mathrm{~cm}^{-1}$ and $2854 \mathrm{~cm}^{-1}\left(2858 \mathrm{~cm}^{-1}\right.$ of $\mathrm{BC}_{6} \mathrm{TMS}$, trace a) respectively, suggestive of conformationally disordered alkyl chains (gauche). After visible light polymerization, the positions of the methylene stretching modes of all the 

$2922 \mathrm{~cm}^{-1}$ and $2851 \mathrm{~cm}^{-1}\left(2856 \mathrm{~cm}^{-1}\right.$ of $\mathrm{BC}_{6} \mathrm{SQ}$, trace a) respectively, indicating a high proportion of trans conformation of alkylene bridged chains (35). Further, the narrow full width at half maximum (fwhm) values of $d^{-}$and $d^{+}$for $\mathrm{BC}_{6} \mathrm{SQ}$ (trace $\mathbf{a}, 20$ and $15 \mathrm{~cm}^{-1}$ ), $\mathrm{BC}_{8} \mathrm{SQ}$ (trace $\mathbf{b}, 17$ and $15 \mathrm{~cm}^{-1}$ ) and $\mathrm{BC}_{10} \mathrm{SQ}$ (trace $\mathbf{c}, 17$

211 and $14 \mathrm{~cm}^{-1}$ ) were consistent with values observed for highly crystalline poly( $n$-octadecyl silsesquioxane)

212 (15 and $11 \mathrm{~cm}^{-1}$ ) (32). These FTIR data provided another evidence for ordered alkylene bridged 213 polysilsesquioxane films.

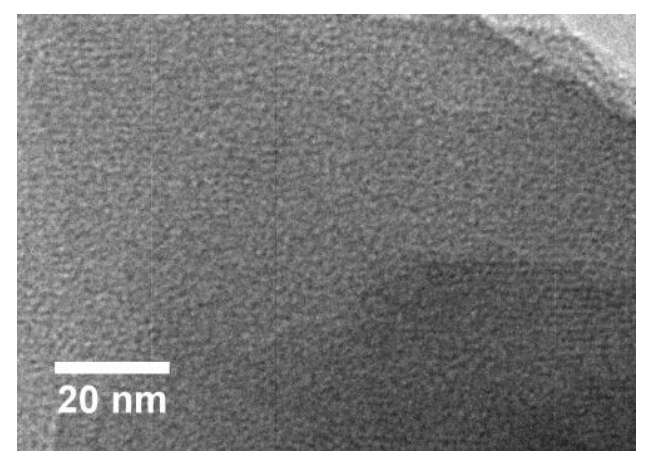

215 Figure 5. TEM image of the visible light cured $\mathrm{BC}_{10} \mathrm{SQ}$ hybrid film.

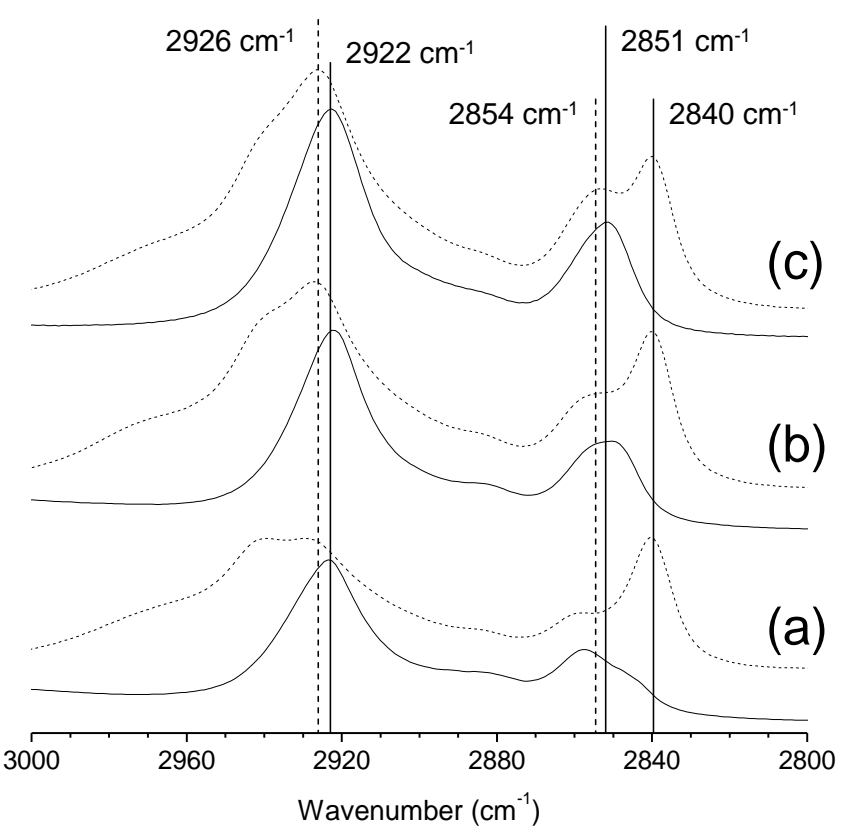

217 Figure 6. Comparison between the FT-IR spectra of the visible light cured $\mathrm{BC}_{\mathrm{n}} \mathrm{PS}(-)$ and $\mathrm{BC}_{\mathrm{n}} \mathrm{TMS}$ precursor (---) at C-H stretching region $[\mathrm{n}=6(\mathbf{a}), 8(\mathbf{b}), 10(\mathbf{c})]$. 


\subsection{Molecular modeling of the ordered polysilsesquioxane structure}

Although an extensive computational effort has been made to study of organosilane self-assembled monolayers (SAMs) (38) as regards to chain thickness, packing and tilt angle, very few molecular simulation studies have focused on ordered SQs. Molecular modeling techniques based on Molecular Mechanics (MM) and/or Density Functional Theory (DFT) could be of utility for elucidating the ordering process and the final structure of the self-assembled organosilica. Recently, Jiang et al. used the quantum chemical modeling in order to clarify the microscopic structure of the investigated organosilane (11). Bantignies et al. combined the FTIR and XRD to the DFT based molecular modeling in order to depict the organic fragments long range structuring (39), and Dieudonné applied molecular mechanics to prepare a microscopic model of the synthesized organo-bridged SQ (40). Finally, molecular DFT was successfully applied to study the Si-C bond cleavage of organosilane precursors during polycondensation to organosilica hybrids (41) and the geometries and energies of several organosilicate molecules in the gas phase (42).

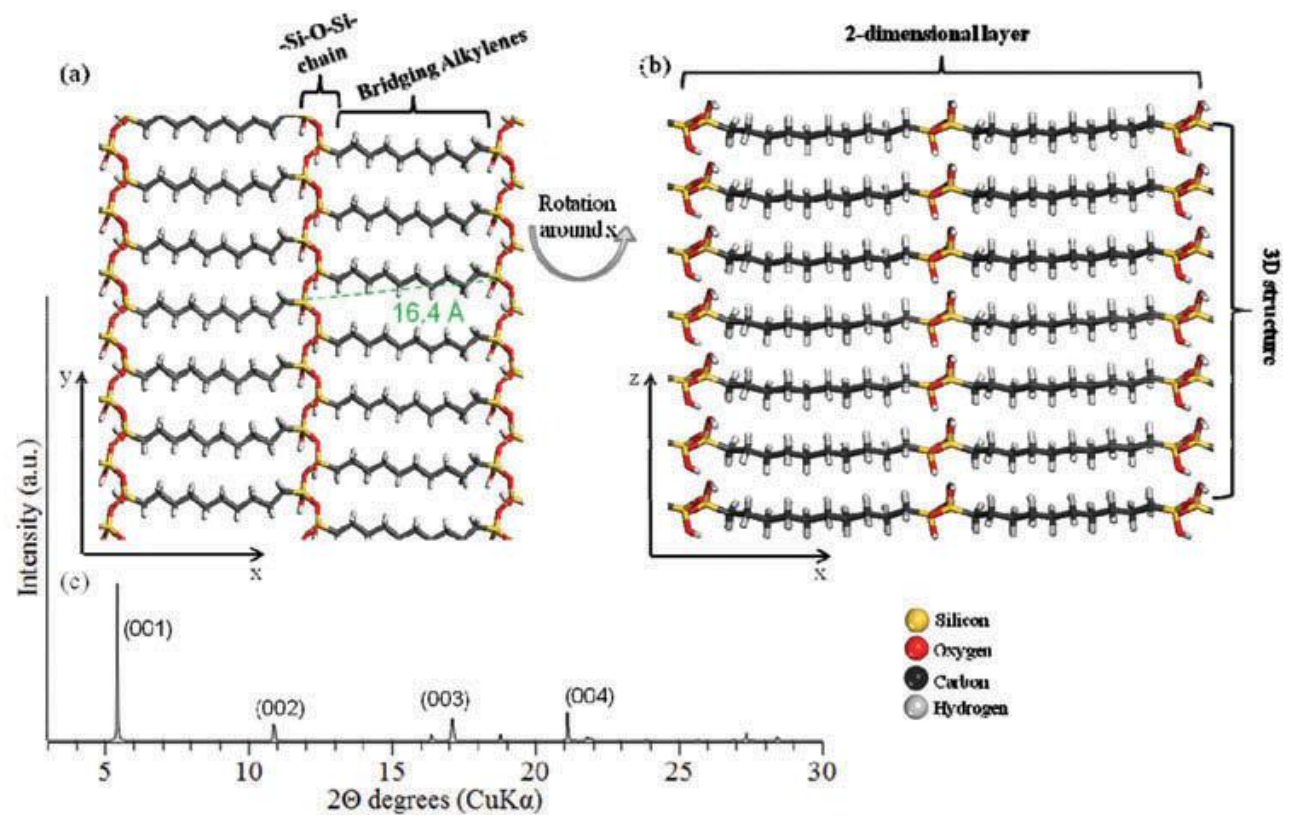

Figure 7. Modeling of bridged silsesquioxane lamellar mesostructure formed by the self-assembly and condensation of $\left(\mathrm{CH}_{3} \mathrm{O}\right)_{3} \mathrm{SiC}_{10} \mathrm{H}_{20} \mathrm{Si}\left(\mathrm{OCH}_{3}\right)_{3}$ precursors: (a) the two-dimensional network formed by -Si-O-Si- condensed linear and parallel chains with thebridging alkylenes with the interlayer distance of 16.4 A. (b) The three-dimensional structure created by stacking the two dimensional layers. (c) The simulated XRD patterns for such a prepared model. 
In the present study, we used molecular modeling to achieve a realistic microscopic model of the

bridged SQ lamellar structures, possibly matching the aforementioned experimental data. The starting structural model for geometry optimization was based upon lamellar d-spacing value (XRD data), trans alkylene chains conformation (FTIR data), and a majority of $\mathrm{T}^{2}$ siloxane species (NMR data). When building the theoretical model of the nanolayer, two head-to-head and the head-to-tail packings were found to be possible. While a head-to-head arrangement yields a double -(Si-O-Si) $)_{n}$ polysiloxane central chain, with alkyl chains of adjacent $\mathrm{Si}$ atoms pointing towards the same direction (not represented here), a head-to-tail assembly leads to a single -( $\mathrm{Si}-\mathrm{O}-\mathrm{Si})_{\mathrm{n}}$ - backbone, with alkyl chains attached to adjacent $\mathrm{Si}$ atoms showing up and down orientation. Due to the steric hindrance imposed by the alkylene chains, the first model was ruled out and only the second "head-to-tail packed" model was considered for further geometry optimization as represented in Figure 7. For sake of simplicity, this theoretical model comprises $\mathrm{T}^{2}$ siloxane species, consequently each silicon atom carries one terminal $\mathrm{OH}$ group. Under this conditions of condensation, the bis-silylated molecular precursors condensed into a two-dimensional network of linear and parallel -(Si-O-Si) $)_{n}-$ chains (Figure 7a). Stacking these 2D structures in the direction perpendicular the plane resulted in a 3D lamellar structure (Figure $7 b$ ). In our model the predominating interaction between two layers corresponds to strong hydrogen bonds formed between dangling hydroxyl groups. Moreover, the existence of experimentally evidenced more condensed $\mathrm{T}^{3}$ species (20-35\%) suggests the formation of orthogonal siloxane links between these planes. Presumably, a too high condensation degree can induce constraints, which may alter the level of ordering. Interestingly, the theoretical interlayer distances obtained from the geometry optimization were in a good agreement with the experimental ones $(12.5 \AA, 14.4 \AA$ and $16.4 \AA$ from simulation versus $12.3 \AA, 14.2 \AA$ and $16.2 \AA$ from experimental measurements). The optimized molecular models of the SQ layers have revealed systems of closely packed chains in extended all-trans conformations. 
The typical distances separating hydrogen atoms of two neighboring alkyl chains were comprised between $2.6-2.9 \AA ̊$.

\subsection{Self-assembly mechanism}

As sol-gel photopolymerization proceeds in bulk and not excess in water or polar solvents as described

for most examples of the literature, self-assembly is no longer entropy-driven but becomes enthalpy-driven,

which can be advantageous as regards self-assembly. The enthalpic cohesive forces (negative $\Delta \mathrm{H}$ ) depend non only from van der Waals forces between alkyl chains but also the solvophobic forces that emanates from the less favorable interactions between surfactant alkyl chains and water molecules (provided by the atmosphere) compared to the more favorable water-water interactions. The magnitude of the solvophobic forces can be thus related to the interfacial tension (water/hydrocarbon $=45 \mathrm{~mJ} \mathrm{~m}{ }^{-2}$ ) and poorly on alkyl chain length. The fact that water has not been added does not mean that it does not play a significant role. Thin film conditions and high relative humidity ensures the presence of water-saturated film. As a result, in a light induced self-assembly, the active role in the assembling process lies preferentially in the medium (water molecules) rather than in the alkyl length. The cohesive forces are not negligible but add as additional alkylenesilanes to self-assemble. suggested that the $n$-propanesulfonic photoacid produced at $405 \mathrm{~nm}\left(0.1 \mathrm{~mW} / \mathrm{cm}^{2}\right)$ and ambient temperature was efficient enough to catalyze the hydrolysis and polycondensation reactions, yielding well-condensed a 
281 siloxane network. Very low exitance and visible light irradiation open perspective for the use of 282 sunlight-induced polymerization, which could be of interest for coating deposition and outdoor 283 self-photopolymerization. Precise control of the sol-gel process (slow condensation, absence of organic 284 solvents) takes maximum advantage of the noncovalent interactions between conjugated alkylene moieties, 285 as well as solvophilic interactions. The most important achievement is that ordering was possible with the 286 minimalist building block $\mathrm{BC}_{6}$ TMS. We believe the use of our sustainable approach can be useful to access 287 novel ordered SQs structures with a much broader range of organosilanes, normally poorly conducive to 288 self-assemble by conventional sol-gel process. The replacement or chemical modification of the alkyl group 289 by functional groups opens avenue for more technology advanced applications.

\section{Acknowledgements}

Dr. Lingli Ni would like to thank the financial support from the National Natural Science Foundation of

293 China (No. 51503072), and Natural Science Foundation of Jiangsu Province (No. BK20150419). 


\section{References}

1. Chemtob, A.; Ni, L.; Croutxé-Barghorn, C.; Boury B. (2014) Ordered Hybrids from Template-Free Organosilane Self-Assembly. Chem. Eur. J., 20: 1790-1806

2. Fujita, S.; Inagaki, S. (2008) Self-Organization of Organosilica Solids with Molecular-Scale and Mesoscale Periodicities. Chem. Mater., 20: 891-908

3. Shimojima, A.; Kuroda, K. (2006) Designed synthesis of nanostructured siloxane-organic hybrids from amphiphilic silicon-based precursors. Chem. Rec., 6: 53-63

4. Lerouge, F.; Cerveau, G.; Corriu, R.J.P. (2006) The van der Waals induced supramolecular organization of hydrophobic tetrahedral units in the course of hydrolytic polycondensation. New J. Chem., 30: 272-276

5. Moreau, J.J.E.; Vellutini, L. ; Bied, C. ; Wong Chi Man, M. (2004) New Approach for the Organisation and the Shaping of Organo-Bridged Silicas: An Overview. J. Sol-Gel Sci. Technol., 31: 151-156

6. Takahashi, M. ; Figus, C.; Kichob, T.; Enzo, S.; Casula, M.; Innocenzi, P. (2009) Self-Organized Nanocrystalline Organosilicates in Organic-Inorganic Hybrid Films. Adv. Mater., 21: 1732-1736

7. Guo, S.; Matsukawa, K.; Miyata, T.; Okubo, T.; Kuroda, K.; Shimojima, A. (2015) Photoinduced Bending of Self-Assembled Azobenzene-Siloxane Hybrid. J. Am. Chem. Soc., 137: 15434-15440

8. Fujii, K.; Kodama, H.; Iyi, N.; Fujita, T.; Kitamura, K.; Sato, H.; Yamagishi, A.; Hayashi, S. (2013) Reversibly meltable layered alkylsiloxanes with melting points controllable by alkyl chain lengths. New J. Chem., 37: 1142-1149

9. Pichon, B.P.; Scampini, S.; Bied, C.; Moreau, J.J.E.; Wong Chi Man M. (2012) The Influence of Arylene and Alkylene Units on the Structuring of Urea-Based Bridged Silsesquioxanes. Eur. J. Inorg. Chem., 2012: $5312-5322$

10. Shimojima, A.; Kuge, H.; Kuroda, K. (2011) Synthesis of mesostructured silica from monoalkyl-substituted double five-ring units. J. Sol-Gel Sci. Technol., 57: 263-268

11. Jiang, J. ; Lima, O.V. ; Pei, Y. ; Jiang, Z. ; Chen, Z. ; Yu, C.; Wang, J.; Zeng, X. ; Forsythe, E.; Tan, L. (2010) Self-Assembled Nanolayers of Conjugated Silane with $\pi-\pi$ Interlocking. ACS Nano, 4: 3773-3780

12. Besson, E. ; Mehdi, A. ; Reyé, C. ; Gaveau, P. ; Corriu, R.J.P. (2010) Self-assembly of layered organosilicas based on weak intermolecular interactions. Dalton Trans., 39: 7534-7539

13. Jiang, J.; Lima, O.V.; Pei, Y.; Zeng, X.C.; Tan, L.; Forsythe E. (2009) Dipole-Induced, Thermally Stable Lamellar Structure by Polar Aromatic Silane. J. Am. Chem. Soc., 131: 900-901

14. Boury, B.; Corriu, R. (2003) Auto-Organization in Sol-Gel Type Polycondensation: A Door to the Nanosciences. Chem. Rec., 3: 120-132

15. Wahab, M.A.; He, C. (2009) Hydrogen-Bond Directed Self-Organized Lamellar Nanostructured Benzene Bridged-Polysilsesquioxane Free-Standing Monolithic Structures via sol-gel Method. Soft Mater., 7: 79 - 92

16. Kuroda, K.; Shimojima, A.; Kawahara, K.; Wakabayashi, R.; Tamura, Y. (2014) Utilization of Alkoxysilyl Groups for the Creation of Structurally Controlled Siloxane-Based Nanomaterials. Chem. Mater., 26: 211-220

17. Mehdi, A.; Reye, C.; Corriu, R. (2011) From molecular chemistry to hybrid nanomaterials. Design and functionalization. Chem. Soc. Rev., 40: 563-574

18. Ni, L. ; Chemtob, A. ; Croutxé-Barghorn, C. ; Dietlin, C. ; Brendlé, J. (2015) Photoinduced self-assembly of carboxylic acid-terminated lamellar silsesquioxane: highly functional films for attaching and patterning amino-based ligands. RSC Adv., 5: 45703-45709

19. Ni, L.; Chemtob, A.; Croutxé-Barghorn, C.; Brendlé, J. ; Vidal, L. ; Rigolet, S. (2012) Kinetics, Thermodynamics, and Dynamics in Organosilane Self-Assembly. J. Phys. Chem. C, 116: 24320-24330

20. Ni, L.; Chemtob, A.; Croutxé-Barghorn, C.; Brendlé, J. ; Vidal, L. ; Rigolet, S. (2012) Photoinduced synthesis and ordering of lamellar n-alkylsiloxane films. J. Mater. Chem., 22: 643-652 
21. Chemtob, A.; Ni, L.; Croutxé-Barghorn, C.; Demarest, A.; Brendlé, J. (2011) Self-Organized Poly(n-octadecylsilsesquioxane) Films via Sol-Gel Photopolymerization. Langmuir, 27: 12621-12629

22. Nunes, S.C.; Bürglová, K. ; Hodačová, J.; Ferreira, R.A.S. ; Carlos, L.D. (2015) Nanostructuring of Bridged Organosilane Precursors with Pendant Alkyl Chains. Eur. J. Inorg. Chem., 2015: 1218-1225

23. Ben, F.; Boury, B.; Corriu, R.J.P.; Le Strat, V. (2000) Evidence for an Organization of Nanostructured Silica-Based Hybrid Materials Prepared by Sol-Gel Polymerization. Chem. Mater, 12: 3249-3252

24. Rosen, M.J.; Kunjappu, J.T. (2012) Surfactants and Interfacial Phenomena. John Wiley \& Sons: New York

25. Zhou, X. ; Yang, S. ; Yu, C. ; Li, Z. ; Yan, X. (2006) Hexylene- and Octylene-Bridged Polysilsesquioxane Hybrid Crystals Self-Assembled by Dimeric Building Blocks with Ring Structures. Chem. Eur. J., 12: 8484-8490

26. Shi, S.; Allonas, X.; Croutxe-Barghorn, C.; Chemtob, A. (2015) Activation of the sol-gel process by visible light-emitting diodes (LEDs) for the synthesis of inorganic films. New J. Chem., 39: 5686-5693

27. Dietlin, C.; Schweizer, S., Xiao, P.; Zhang, J.; Morlet-Savary, F. (2015) Photopolymerization upon LEDs: new photoinitiating systems and strategies. Polym. Chem., 6: 3895-3912

28. Courtecuisse, F.; Cerezo, J.; Croutxé-Barghorn, C.; Dietlin, C.; Allonas, X. (2013) Depth characterization by confocal raman microscopy of oxygen inhibition in free radical photopolymerization of acrylates: Contribution of the thiol chemistry. J. Polym. Sci., Part A: Polym. Chem., 51: 635-643

29. Kenning, N.S.; Ficek, B.A.; Hoppe, C.C.; Scranton, A.B. (2008) Spatial and temporal evolution of the photoinitiation rate for thick polymer systems illuminated by polychromatic light: selection of efficient photoinitiators for LED or mercury lamps. Polym. Int., 57: 1134-1140

30. Oviatt, H.W.; Shea, K.J.; Small, J.H. (1993) Alkylene-bridged silsesquioxane sol-gel synthesis and xerogel characterization. Molecular requirements for porosity. Chem. Mater., 5: 943-950

31. Asakura, T.; Yamato, H.; Tanaka, K.; Takahashi, R.; Kura, H.; Nakano, T. (2014) Studies on Photodecomposition of an Oxime Sulfonate. J. Photopolym. Sci. Tec., 27: 227-30

32. Parikh, A.N.; Schivley, M.A.; Koo, E.; Seshadri, K.; Aurentz, D. (1997) n-Alkylsiloxanes: From Single Monolayers to Layered Crystals. The Formation of Crystalline Polymers from the Hydrolysis of n-Octadecyltrichlorosilane. J. Am. Chem. Soc., 119: 3135-3143

33. Loy, D.A.; Mather, B.; Straumanis, A.R.; Baugher, C.; Schneider, D.A. (2004) Effect of pH on the Gelation Time of Hexylene-Bridged Polysilsesquioxanes. Chem. Mater, 16: 2041-2043

34. Hoffmann, F., Cornelius, M., Morell, J., and Fröba, M. (2006) Silica-based mesoporous organic-inorganic hybrid materials. Angew. Chem. Int. Ed., 45:3216 - 3251.

35. Bantignies, J.L. ; Vellutini, L. ; Maurin, D. ; Hermet, P. ; Dieudonne, P. (2006) Insights into the Self-Directed Structuring of Hybrid Organic-Inorganic Silicas through Infrared Studies. J. Phys. Chem. B, 110: 15797-15802

36. Hostetler, M.J.; Stokes, J.J.; Murray, R.W. (1996) Infrared Spectroscopy of Three-Dimensional Self-Assembled Monolayers: N-Alkanethiolate Monolayers on Gold Cluster Compounds. Langmuir, 12: 3604-3612

37. Snyder, R.G.; Strauss, H.L.; Elliger, C.A. ; (1982) Carbon-hydrogen stretching modes and the structure of n-alkyl chains. 1. Long, disordered chains. J. Phys. Chem., 86: 5145-5150

38. Castillo, J.M.; Klos, M.; Jacobs, K.; Horsch, M.; Hasse, H. (2015) Characterization of Alkylsilane Self-Assembled Monolayers by Molecular Simulation. Langmuir, 31: 2630-2638

39. Creff, G.; Arrachart, G.; Hermet, P.; Wadepohl, H.; Almairac. R. (2012) Investigation on the vibrational and structural properties of a self-structured bridged silsesquioxane. Phys. Chem. Chem. Phys., 14: 5672-5679

40. Dieudonné, P.; Wong Chi Man M.; Pichon, B.P.; Vellutini, L.; Bantignies, J.L. (2009) In situ X-ray Measurements to Probe a New Solid-State Polycondensation Mechanism for the Design of Supramolecular Organo-Bridged Silsesquioxanes. Small, 5: 503-510

41. Shirai, S. ; Goto, Y. ; Mizoshita, N. ; Ohashi, M. ; Tani, T. (2010) Theoretical Studies on Si-C Bond Cleavage in 
42. Futamura, R.; Jorge, M.; Gomes.; J.R.B. (2013) Structures and energetics of organosilanes in the gaseous phase: a computational study. Theor. Chem. Acc., 132: 1-10 